\title{
A Identidade da Direita em Narrativas de seus Militantes numa Universidade Brasileira
}

\author{
Renan Silva de Sousa ${ }^{1}$ \\ ${ }^{1}$ Universidade Federal da Paraíba, PB, Brasil. \\ Pedro de Oliveira Filho ${ }^{2}$ \\ ${ }^{2}$ Universidade Federal de Campina Grande, PB, Brasil.
}

\author{
Jônatas Barros Araújo² \\ ${ }^{2}$ Universidade Federal de Campina Grande, PB, Brasil. \\ Dandara Virgínia Machado Vieira ${ }^{2}$ \\ ${ }^{2}$ Universidade Federal de Campina Grande, PB, Brasil.
}

Resumo: Em junho de 2013, emergiram no espaço público brasileiro diferentes grupos de direita rebelados contra o Partido dos Trabalhadores, que governava o Brasil naquele momento liderando uma grande coalizão de centro-esquerda. Desde então, uma nova direita se posiciona no debate político nacional, militando nas universidades e em outros contextos institucionais e mobilizando uma retórica agressiva contra o discurso de esquerda. O objetivo deste estudo é identificar os diferentes atributos da identidade da direita formulados em narrativas de militantes de direita de uma universidade pública brasileira, as contradições no conteúdo dessa identidade e os recursos retórico-discursivos mobilizados em sua construção. Com o uso do método de análise de discurso, foram analisadas transcrições de entrevistas realizadas com nove militantes de direita, alunos de uma universidade pública nordestina. Esses militantes mencionam três grupos políticos como constituintes da direita (os conservadores, os liberais e os libertários), mas somente dois são usados como categorias de autoidentificação: os conservadores e os libertários. Atributos identitários como o apreço pela verdade, a defesa da liberdade, a desconfiança em relação às mudanças abruptas e a valorização da família e da religiosidade cristã foram afirmados como definidores da identidade da direita. Em vários momentos, no entanto, os militantes produziam enunciados que contradiziam alguns desses atributos, revelando o caráter ambíguo e contraditório do discurso da militância estudada.

Palavras-chave: Identidade, Direita, Discurso.

\section{The Identity of the Right-Wing in Narratives of its Militants in a Brazilian University}

\begin{abstract}
In June 2013, different right-wing groups emerged in the Brazilian public space rebelling against the Partido dos Trabalhadores, which ruled Brazil at the time leading a large center-left coalition. Since then, a new right-wing has positioned itself in the national political debate, militating in universities and other institutional contexts, and mobilizing an aggressive rhetoric against the leftist discourse. This study aims to identify the different attributes of the right-wing identity formulated in the narratives of right-wing militants in a Brazilian public university, the contradictions in the content of that identity, and the rhetorical-discursive resources mobilized in its construction. We analyzed transcripts of interviews conducted with nine right-wing activists, students from a public university in the Northeast using the speech analysis method. These militants mention three political groups as constituents of the right-wing (conservatives, liberals, and libertarians), but only two are used as categories of self-identification: conservatives and libertarians. Identity attributes such as an appreciation for the truth, the defense of freedom, a distrust of abrupt changes, and the appreciation for the
\end{abstract}


family and Christian religiosity were affirmed as defining the identity of the right-wing. At various times, however, the militants produced statements that contradicted some of these attributes, revealing the ambiguous and contradictory character of the studied militancy discourse.

Keywords: Identity, Right-wing, Discourse.

\title{
La Identidad de la Derecha en las Narrativas de sus Militantes en una Universidad Brasileña
}

\begin{abstract}
Resumen: En junio de 2013, diversos grupos de derecha rebelaban contra el Partido de los Trabajadores, que gobernaba Brasil en ese momento liderando una gran coalición de centro-izquierda. Desde entonces, una nueva derecha se ha posicionado en el debate político nacional, militante en universidades y otros contextos institucionales, y movilizando una retórica agresiva contra el discurso de izquierda. El objetivo de este estudio es identificar los diferentes atributos de la identidad de derecha formulados en las narrativas de activistas de derecha en una universidad pública brasileña, sus contradicciones y los recursos retórico-discursivos movilizados. Como método el análisis del discurso, se analizaron las transcripciones de entrevistas realizadas a nueve activistas de derecha, estudiantes de una universidad pública del Nordeste (Brasil). Estos militantes mencionaron tres grupos políticos como constituyentes de la derecha (los conservadores, los liberales y los libertarios), pero solo dos utilizan las categorías de autoidentificación: los conservadores y los libertarios. Los atributos identitarios como el aprecio a la verdad, la defensa de la libertad, la desconfianza ante los cambios bruscos y el aprecio a la familia y la religiosidad cristiana fueron considerados definitorios de la identidad de derecha. En varias ocasiones, los militantes contradijeron algunos de estos atributos, revelando el carácter ambiguo y contradictorio del discurso de la militancia estudiado.
\end{abstract}

Palabras clave: Identidad, Derecha, Discurso.

\section{Introdução}

Com a ascensão dos governos neoliberais de Margaret Thatcher na Inglaterra e Ronald Reagan nos Estados Unidos, a partir do final dos anos 1970, e posteriormente com a queda do muro de Berlim e o colapso da União Soviética, o liberalismo econômico voltou a influenciar decisivamente a forma de organização das sociedades ocidentais. O neoliberalismo triunfante dos governos de direita de Thatcher e Reagan adotou um conjunto de medidas que visavam destruir o keynesianismo e o welfare state: privatizações, elevação de taxas de juros, redução drástica de impostos sobre altos rendimentos, abolição do controle sobre fluxos financeiros etc. Esses governos neoliberais impulsionaram uma nova compreensão sobre o papel do Estado na vida social que, a partir de então, tornou-se hegemônica (Anderson, 1995).

Como um contraponto à direita neoliberal, diversos movimentos sociais constituem na atualidade uma direita nacionalista, como é o caso de movimentos de extrema-direita na Europa e de parte dos diversos grupos e movimentos sociais que levaram Donald Trump ao poder nos Estados Unidos. Esses movimentos combatem o neoliberalismo em razão de seu internacionalismo, de seu liberalismo nos costumes e de seu desprezo pelos valores tradicionais do nacionalismo (Finguerut \& Souza, 2018).

No Brasil recente, no entanto, essa ultradireita nacionalista se aliou aos grupos neoliberais em 2015 nas grandes mobilizações de rua pró-impeachment de Dilma Rousseff, presidente da república eleita pelo Partido dos Trabalhadores (Delcourt, 2016), e recebeu o apoio desses mesmos grupos neoliberais na campanha vitoriosa de Jair Bolsonaro à presidência da república em 2018 (Santos, 2018).

Os eventos de 2015 estão entre os mais importantes no processo de irrupção desses grupos de direita no espaço público brasileiro. Dois anos antes de 2015, 
nas manifestações de junho de 2013, que se apresentaram inicialmente como apartidárias, esses grupos ocuparam o centro do palco político e dele não saíram mais. Os protestos de rua, iniciados como uma resposta de manifestantes de esquerda à violência policial, logo foram ocupados por grupos de direita mobilizados pelo discurso da anticorrupção e pelo antipetismo. Essa clivagem ideológica se manifestará na forma de conflitos no interior das manifestações, entre grupos de direita e esquerda (Abreu \& Allegretti, 2016; Brugnago \& Chaia, 2015; Safatle, 2017).

Esses eventos deram início à ocupação do espaço público pela direita. Esse fenômeno, como não poderia deixar de ser, tem ocorrido também nas universidades brasileiras. Numa reportagem publicada no site do Jornal Estadão, cujo título é "À direita, MBL disputa espaço entre estudantes”, Martins (2016) afirma: “. . o MBL já tem atuação em chapas de universidades (públicas e privadas), representação em centros acadêmicos e grêmios estudantis".

A organização e a visibilidade desses grupos nas universidades indicam uma mudança inquestionável na cena política brasileira. Após o fim da ditadura militar, os grupos políticos estudantis eram predominantemente de esquerda ou de centro. Um estudo recente de Brenner (2011) evidencia a irrelevância de grupos organizados de direita nas universidades públicas brasileiras antes de 2013; irrelevância que tem uma óbvia relação com a derrocada da ditadura militar, derrocada que, como argumentam Madeira e Tarouco (2011), produziu como resultado o fenômeno da "direita envergonhada".

Depois de 2013, no entanto, emergiu uma militância estudantil de direita na universidade pública brasileira, sem vergonha de dizer seu nome e com o objetivo claro de produzir subjetividades e identidades políticas no meio estudantil que sejam alinhadas com o pensamento de direita.

Este estudo procura compreender esses novos movimentos de direita no Brasil, investigando o modo como militantes de direita em uma universidade pública definem a si mesmos e a corrente política que constituem com suas ações. O conceito de identidade é central nesta investigação. Processos identitários são compreendidos aqui como fenômenos discursivos de natureza classificatória que pertencem fundamentalmente ao espaço público do discurso e da argumentação (Antaki \& Widdicombe, 2008; Benwell \& Stokoe, 2006; Billig, 1987; Edwards, 2008; Potter, 1998;
Potter \& Wetherell, 1987; Wetherell, 2008; Wetherell \& Potter, 1992), processos marcados por disputa, negociação e conflito (Benwell \& Stokoe, 2006).

São fenômenos discursivos de natureza classificatória porque pessoas e grupos passam a ter identidades quando são inseridos, por eles mesmos ou por outras pessoas e grupos, em categorias (Antaki \& Widdicombe, 2008) - "João é conservador", "esse grupo é conservador" - às quais estão associados diferentes atributos - "conservadores são puritanos", "conservadores são religiosos" etc. As identidades, assim, são constituídas discursivamente, e não produtos que emergem necessariamente da posição de indivíduos e grupos na estrutura social; por isso mesmo, são precárias, contingentes, contraditórias e marcadas pela ameaça iminente de fragmentação (Laclau \& Mouffe, 2015).

Diferenciar identidades de pessoas e de grupos é simplesmente reconhecer, conforme Jenkins (2004), que identificar grupos é diferente de identificar indivíduos. No primeiro caso são constituídas identidades coletivas e no segundo, identidades individuais.

De fato, categorizar um grupo ("nós somos conservadores", "eles são conservadores") é diferente de categorizar um indivíduo ("eu sou conservador", "João é conservador"). Mas nos dois casos o processo é social, marcado por assemelhação e diferenciação. Dizer de um grupo que ele é conservador é assemelhá-lo a todos os outros que são conservadores e diferenciá-lo de todos os outros que não o são. Da mesma forma, dizer de um indivíduo que ele é conservador é assemelhá-lo a todos os indivíduos que são conservadores e diferenciá-lo de todos os outros que não o são.

Os dois processos são interdependentes, pois um indivíduo formula uma identidade para si próprio porque existem identidades coletivas. Por outro lado, no ato de afirmar uma identidade para si ("eu sou socialista"), o indivíduo participa da constituição do grupo do qual faz parte. Como afirma Wetherell (2008) a identificação é um complexo ato de produção de sentido por meio do qual o sujeito, ao constituir discursivamente a si próprio, constitui um mundo.

Mas esse ato de formular uma identidade para si próprio e para os outros nem sempre é simples como na sentença "eu sou socialista". É frequentemente acompanhado por justificativas, argumentações e por uma complexa organização retórica. Analistas de discurso (Benwell \& Stokoe, 2006; Condor, Tileaga, \& Billig, 2013; Edwards, 2008; Potter, 1998; 
Wetherell, 2008; Wetherell \& Potter, 1992) têm mostrado nas últimas décadas, com riqueza de detalhes, toda a sofisticação retórica envolvida na produção de identidades.

Este estudo investiga esse processo no contexto político brasileiro atual. Objetiva-se é identificar os diferentes atributos da identidade da direita formulados em narrativas de militantes de direita em uma universidade pública brasileira, as contradições no conteúdo dessa identidade e os recursos retórico-discursivos mobilizados em sua construção.

\section{Método}

A pesquisa foi realizada em uma universidade pública localizada na região Nordeste do Brasil. Os critérios que orientaram a escolha dos participantes foram os seguintes: estar matriculado em qualquer curso da universidade supracitada, ter mais de 18 anos e militar publicamente em algum grupo de direita. Os participantes deste estudo organizavam e mobilizavam a militância de direita em diferentes grupos de discussão política nas redes sociais, mas também organizavam debates e eventos em ambientes não virtuais. Alguns dos militantes que participaram deste estudo, por exemplo, organizaram no interior da universidade a exibição, seguida de debate, do filme O Jardim das Aflições, longa que apresenta a vida e a obra de Olavo de Carvalho, um dos mais importantes ideólogos da ultradireita nacional. A exibição do filme atraiu militantes de direita de outras cidades e ocorreu num clima de grande tensão porque alguns grupos de esquerda tentaram, sem sucesso, impedir a realização do evento.

Para ter acesso aos militantes utilizou-se a amostragem em bola de neve. Trata-se de uma amostragem não probabilística, muito "útil para estudar determinados grupos difíceis de serem acessados" (Vinuto, 2014, p. 203). Primeiramente entrevistou-se um informante-chave, já conhecido pelos pesquisadores, e, a partir dele, foram localizados outros militantes de direita que também foram entrevistados.

Para nortear as entrevistas utilizou-se um roteiro de entrevista semiestruturada com questões relacionadas à direita, a seus adversários e ao debate político nacional. A princípio se pretendia realizar entrevistas grupais, com grupos de três alunos. Algumas de fato foram realizadas em grupo. Porém, as dificuldades crescentes para viabilizar entrevistas em grupo e o desejo de ampliar o número de participantes para que a amostra fosse representativa das diferentes tendências de direita na universidade em questão, determinaram mudanças na intenção inicial. Foram realizadas seis entrevistas com nove militantes de direita, todos referidos com nomes fictícios neste estudo. Uma delas com um grupo de três militantes conservadores (Eurico, Luís e Alfredo), outra com uma dupla de militantes conservadores (José e Ademir) e quatro entrevistas individuais, com dois militantes conservadores (Paula e Carlos Eduardo) e dois libertários (César e Emerson). Todas as entrevistas foram gravadas, com a permissão dos participantes, e posteriormente transcritas. Este estudo se detém somente sobre uma parte dos conteúdos analisados, aqueles que dizem respeito ao modo como a militância define a si mesma e à direita política de uma forma geral.

O mais novo desses militantes tinha 18 anos e o mais velho, 36 anos anos. Dos nove militantes entrevistados, oito eram homens e uma era mulher. No que diz respeito à filiação religiosa, quatro eram evangélicos, dois eram católicos, um era espírita e dois eram agnósticos. No que diz respeito à cor/raça, quatro se definiram como brancos e cinco como pardos. As rendas de seis dos militantes variavam de 1.400 a 4.000 reais. Um deles tinha uma renda familiar de 35.000 reais e dois não souberam informar. Dos nove militantes, quatro cursavam história, dois cursavam engenharia, um cursava ciências econômicas e um cursava psicologia.

A categoria militância não foi usada pelos participantes para descrever suas atividades políticas. Trata-se de uma categoria dos pesquisadores, no entanto, quando foi usada pelos entrevistadores nas entrevistas, só foi recusada por dois participantes conservadores, Luís e Eurico. Para Luís o termo seria muito associado à esquerda e Eurico entendeu que não tinha todos os atributos de um militante. Os pesquisadores usaram o termo militância porque não tinham, e não têm, dúvidas de que a partir de 2013 emergiu uma inequívoca militância de direita no Brasil: pessoas que disponibilizam uma parte de seu tempo para defender, por convicção, os valores da direita. Ademais, o termo não é usado exclusivamente para nomear membros de grupos de esquerda, como indicam diferentes trabalhos que o usam para nomear os grupos da nova direita que surgiu em 2013 (Brugnago \& Chaia, 2015; Delcourt, 2016; Rocha, 2019 ). Por fim, nada indica que o termo ativismo, muito presente no vocabulário dos libertários de esquerda (ver Sales, Fontes, \& Yasui, 2018), 
teria mais aceitação entre os membros dos diferentes grupos de direita no Brasil do que o termo militante.

O projeto de pesquisa que gerou este estudo foi aprovado pelo Comitê de Ética em Pesquisa da universidade pública onde ocorreu a pesquisa (CAAE: 72115417.0.0000.5182). Os participantes assinaram o Termo de Consentimento Livre e Esclarecido que, entre outros esclarecimentos, descrevia os objetivos da pesquisa e informava que eles poderiam interromper sua participação a qualquer momento.

\section{Codificação e análise}

No método de análise de discurso que orienta a análise aqui apresentada, primeiramente realiza-se uma codificação, guiada pelas questões de pesquisa, codificação que organiza em categorias o material discursivo (Gill, 2002; Potter \& Wetherell, 1987). Nesteestudo objetode pesquisaéaidentidadedadireita em relatos dos militantes de direita. Assim, todas as passagens no material discursivo em que os militantes definiam de alguma forma a si mesmos e a direita política foram identificadas e organizadas em categorias. Esse trabalho de codificação antecedeu uma análise mais minuciosa, uma análise atenta à organização retórica e às funções do discurso, às diferentes ações que ele realiza (Gill, 2002; Potter \&Wetherell, 1987).

\section{Resultados e discussão}

\section{Definindo a direita}

Os estudantes construíram diferentes posições identitárias para a militância de direita na universidade e para a direita de uma forma geral. Quando mencionavam especificamente os estudantes de direita no interior da universidade, a discriminação supostamente sofrida por eles foi um dos temas mais recorrentes.

A universidade não é só de vocês, desses grupos revolucionários que se acham donos, que não permitem a existência de outros pensamentos (Paula).

Hoje, principalmente quando você vai cursar um curso no campo das ciências humanas, você não pode ter uma expressão de um pensamento conservador ou liberal, você é ferrenhamente atacado, ferrenhamente perseguido, eh... Conheço pessoas que foram vítimas de per- seguição, que tiveram que trancar cadeiras por causa de perseguição, por se mostrarem a favor de causas que não correspondiam à dos docentes, isso gerou uma polêmica, isso é muito comum dentro de uma universidade do campo das ciências humanas e a direita, ela vem justamente pra isso, pra mostrar que não é só eles que pensam, pra mostrar que não é aquilo que eles pregam que é o certo... E é isso, essa questão da liberdade, de você chegar em uma sala de aula no curso de história, de filosofia, de sociologia e poder citar um John Locke, um Mises, um Adam Smith, sem ser rechaçado, sem ser perseguido ou, até mesmo, uma citação ou alguma obra do professor Olavo de Carvalho que causa tanta repercussão. É você poder citar essas pessoas e encontrar uma compreensão, um entendimento, não você ser perseguido, vocêser rechaçado por pensar diferente. Os fascistas faziam isso na época da segunda guerra mundial, se você pensava diferente, eles iam atrás de você (Luís).

A gente percebe como essa perseguição, ela não precisa ser direta, ela pode ser indireta. Quando eu chego em um ambiente assim todos fecham a cara. Inclusive os meus colegas mais próximos, eles relatam coisas de outros que falaram de mim, então, você acaba ficando famoso no curso, justamente como o fascista, o nazista, de gente que nem sabe o que é o fascismo e o nazismo (Eurico).

Nessas intervenções, a universidade é representada como uma instituição dominada pela esquerda, como um ambiente ameaçador para estudantes de direita. Constroem a esquerda na universidade como um movimento antagônico de teor autoritário, hegemônico, opressivo, intransigente, incapaz de dialogar e até mesmo fascista ("os fascistas faziam isso na época da segunda guerra mundial, se você pensava diferente, eles iam atrás de você"). Esses relatos reproduzem discursos de intelectuais de direita, como Olavo de Carvalho, que há décadas acusam as universidades públicas de serem instituições a serviço das esquerdas (Pinto, 2019).

A direita, por outro lado, é representada como um movimento minoritário, como uma vítima constantemente atacada e silenciada que luta por liberdade e pluralismo na universidade. Essa posição de vítima tem semelhanças com a posição identitária formulada por militantes de direita ultraliberais 
investigados por Rocha (2019). Esses militantes, segundo Rocha (2019, p. 8), expressavam um "sentimento de marginalidade em relação a públicos dominantes", especialmente nos contextos acadêmicos. A autora utiliza o conceito de contrapúblico para entender esse fenômeno. Contrapúblicos seriam grupos, não necessariamente subalternos, que formulariam discursos tão destoantes em relação aos discursos dominantes que poderiam sentir-se hostilizados. Os ultraliberais entrevistados por Rocha (2019) definiam-se como pessoas hostilizadas e menosprezadas por outras correntes liberais e por sociais-democratas, que dominariam os ambientes acadêmicos.

A semelhança não é mero acaso. Os ultraliberais (um outro nome para libertários) estão representados por seus militantes neste estudo. Trata-se de um grupo que, em suas versões mais radicais, reivindica o fim do próprio Estado, e não somente o Estado mínimo. Um outro grupo representado por seus militantes neste estudo é constituído por pessoas que professam um conservadorismo radical. Os militantes que se categorizaram como conservadores aqui declararam apoio explícito à candidatura de Jair Bolsonaro à presidência da república. Os dois grupos, portanto, formulam discursos acentuadamente divergentes em relação ao centro político e até mesmo em relação a outras correntes de direita. Mas, no caso dos conservadores deste estudo, não é somente a divergência de seu pensamento em relação ao padrão dominante na universidade que explicaria essa representação da universidade como um ambiente que hostiliza o pensamento de direita. Sem desconsiderar as eventuais práticas autoritárias de alguns grupos de esquerda contra a expressão de discursos de direita no interior da universidade, pode-se afirmar que o discurso formulado pelos conservadores deste estudo, que retrata a universidade pública como um ambiente opressivo para o pensamento de direita, é mais a reprodução estratégica de um discurso central na identidade da ultradireita bolsonarista e menos o reflexo de uma realidade vivenciada por esses militantes. $\mathrm{O}$ discurso em questão nasce no conservadorismo radical estadunidense e é reproduzido no Brasil por ideólogos do bolsonarismo como Olavo de Carvalho e o General Sérgio Augusto de Avellar Coutinho (Pinto, 2019). Nesse discurso, o marxismo cultural seria a arma utilizada pela esquerda para realizar seu projeto de dominação, cujo dispositivo estaria funcionando com a máxima potência no interior das universidades e de outras instituições brasileiras (Pinto, 2019).
Dois artifícios retóricos são mobilizados por Paula, Eurico e Luís para construir a direita como uma corrente política oprimida na universidade, artifícios usados por eles e por outros militantes para construir também outros atributos identitários da direita. Um deles é a formulação de casos extremos (Pomerantz, 1986): "não permitem a existência de outros pensamentos", "você é ferrenhamente atacado, ferrenhamente perseguido", "quando eu chego em um ambiente assim todos fecham a cara". Outro artifício é o uso de histórias de reconhecida eficácia retórica quando se trata de tornar factuais argumentos desenvolvidos em contextos de conflito intergrupal (van Dijk, 1987; Wetherell \& Potter, 1992). Assim, eles falam daqueles que "trancaram cadeiras por causa de perseguição" ou dos episódios em que os universitários de esquerda "fecham a cara" quando em presença de um militante de direita.

Quando descrevem a direita de forma geral, e não somente a direita na universidade, os participantes deste estudo formulam outras posições identitárias para ela, que colocam em primeiro plano as diferenças no campo da direita, afinal, o discurso da direita é marcado por tensões internas e contradições que são características de todas as identidades, como argumentam diferentes autores (Benwell \& Stokoe, 2006; Jenkins, 2004; Laclau \& Mouffe, 2015).

Três correntes de pensamento são nomeadas nos relatos dos participantes quando falam da direita na universidade: conservadorismo, libertarianismo e liberalismo. No entanto, como já foi relatado, somente duas categorias, conservador e libertário, foram usadas como categorias de autoidentificação. Nas falas abaixo, militantes da direita conservadora descrevem o conservadorismo.

O conservadorismo não é uma ideologia, né? É uma filosofia. Então, assim, as pautas que acabam sendo defendidas pelos conservadores no mundo são as mesmas pautas que, pelo menos no mundo ocidental, são as mesmas pautas que eu defendo (José).

O conservadorismo, ele tenta conservar aquelas diretrizes e os pilares que vão manter a sociedade de uma forma que não fique caótica, por exemplo, o cristianismo, o capitalismo, o direito romano, eh... a filosofia grega, então, eu sou conservador nessa área aí de tentar conservar aquilo que vem 
sendo experimentado ao longo do tempo e são coisas eternas, não são coisas que nós aprendemos assim no Facebook e no outro já ninguém lembra mais (Eurico).

Eu ainda me entendo como um conservador de fato, por conta da questão... questões até religiosas também que influenciam a questão da valorização da família, regressos sociais, esse tipo de coisa.(Alfredo).

Bom, é... moralmente falando, eu sou absolutamente conservador socialmente, só que quando se trata de economia nós vemos como o liberalismo econômico é... talvez a melhor opção para se gerar riquezas e prosperidade de uma sociedade (Eurico).

Nósconservadores, a gente defendeo Estado mínimo também, mas é como eu disse a tu, é... sempre tem aquela preocupação de qualquer mudança a gente analisar, "ah essa mudança, se for mudar isso aqui, quais seriam as consequências de mudar isso aqui?"Entendeu? (Paula).

$E u$, creio que sou conservador, por causa que ainda sigo aqueles costumes, aquelas velhas éticas que já vêm sendo trazidas até hoje. Traduzindo, vindo pela moral, pelas éticas morais, pela coisas que o Estado já vem protegendo até hoje, desde o seu, desde o império, basicamente (Carlos Eduardo).

Como Flavio Morgenstern fala sempre, ele diz que o conservadorismo é o novo sexy, as pessoas estão migrando porque a esquerda tá muito chata. Nós somos a nova contracultura, então por isso que eu digo que a direita no Brasil, em termos nacionais, ela é muito nova, é uma criança ainda (Eurico).

Libertários são minoria ainda menor dentro da direita, assim, é a minoria dentro da minoria da direita. Então, assim, você percebe que certos grupos de direita, eles não entendem a complexidade da realidade, mas com outros liberais eu já consigo ter uma conversa muito tranquila, tudo mais, porque eles entendem essa questão da complexidade da realidade. Porque, por exemplo, os libertários, eles ficam tão preso... eu digo... eu não conheço nenhum que não seja desse jeito de libertários ... Eles ficam tão presos aos livros, a conceitos de mercado e que tudo tem que se gerir de forma privada que eles não entendem que o mundo, ele se concebeu de outra forma, entendeu? Então acabam ficando presos a uma utopia que é como se... tem gente até próprios liberais que falam que os libertários são os marxistas com sinal inverso, assim, sinal da pilha inverso, porque eles também acreditam em uma utopia e nessa utopia pra eles qualquer coisa é válida, entendeu? Essa utopia do mercado (José).

Nessas falas, em meio a temáticas tradicionais e amplamente compartilhadas pelo senso comum conservador, como a adesão à religiosidade cristã e a valorização da família, pode-se notar outras temáticas que são debatidas nos meios intelectuais conservadores.

O primeiro comentário, o de José, descreve o pensamento conservador como uma compreensão de mundo com raízes profundas no mundo ocidental e acrescenta que é um pensamento verdadeiro, não ideológico. Jenkins (2004), referindo-se à identidade coletiva, afirma que uma das coisas que temos em comum é nossa diferença de outros, portanto, quando dizemos algo sobre os outros estamos falando amiúde algo sobre nós. No entanto, o contrário é também verdadeiro: quando afirmamos algo sobre nós também estamos, amiúde, afirmando algo sobre o outro. Sem mencionar a esquerda, José a posiciona tacitamente como uma corrente política caracterizada por produzir um pensamento ilusório, que distorce a realidade, pensamento ideológico, enfim, tal como uma das versões marxistas retrata o conceito de ideologia, presente em Marx e Engels (1998). Aceitam um dos conceitos de ideologia produzidos por dois ícones da esquerda ocidental, que avalia negativamente $o$ fenômeno ideológico, e o usam para acusar as esquerdas de disseminar a falsidade e a ilusão pelo mundo.

Essa representação da esquerda como ideológica é formulada em vários outros momentos das entrevistas. Na fala abaixo, Ademir, um conservador, descreve mais detidamente esse suposto caráter ideológico da esquerda brasileira.

Porque tudo no Brasil é falso, eu, como estudante de história, a gente sabe que até a própria história é falsa, é montada, então a gente precisa entender que no Brasil as coisas precisam funcionar de ah... como elas são e não como a gente cria e acha que vai ser porque é o seguinte, quando eu venho pra uma universidade, um curso de humanas, 
aonde é justamente o lugar a ser debatido novas ideias e porque as novas ideias surgiram e porque existem inquietações e porque existem formações de opiniões divergentes e a gente não pode debater, isso é uma falsa democracia. ... Eu acho que as pessoas precisam entender que no Brasil a gente vive uma ditadura de ideologias, assim como... como José falou e de ditadura de ideologias principalmente dentro dos Centros Acadêmicos onde nós somos formadores de opiniões e vamos nos tornar formadores de opiniões (Ademir).

Ademir inicia seu relato formulando um caso extremo ("tudo no Brasil é falso"), cujo conteúdo dá o tom de tudo o que se segue. Ele não cita diretamente a esquerda, mas ela é responsabilizada tacitamente pela produção dessa ideologia quando ele responsabiliza abertamente determinadas instituições, universidades públicas, centros acadêmicos, pela produção e disseminação da ideologia que aliena a sociedade brasileira ("uma ditadura de ideologias principalmente dentro dos Centros Acadêmicos"), instituições tidas por ideólogos da ultradireita que está no poder no Brasil como essencialmente esquerdistas, como já foi ressaltado.

É importante destacar o contraste entre esse apego à verdade (presente de maneira destacada nas intervenções dos participantes desta pesquisa que se declararam conservadores) e aquilo que se diz sobre a relação entre ultradireita e pós-verdade na atualidade. Como argumenta Silveirinha (2018), a ultradireita europeia e a ultradireita dos Estados Unidos liderada por Trump abusam do pós-verdade, debocham dos fatos e da objetividade científica. Silveirinha (2018, p. 38) sugere que o pensamento pós-moderno, ao afirmar que "temos de nos libertar das categorias binárias (como verdadeiro/falso)" e reconhecer "o carácter ilusório da busca pela verdade", preparou de certa forma o terreno para a pós-verdade. De fato, em seus piores momentos o pensamento pós-moderno pode ter autorizado uma abordagem irresponsável para essa questão, ao sugerir que poderíamos simplesmente dispensar o conceito de verdade, embora seja inquestionável que autores influenciados pelo pragmatismo, como Rorty (1994) e Latour e Woolgar (1997), dentre outros, aumentaram, naquelas duas últimas décadas do século $\mathrm{XX}$, nossa compreensão sobre os limites desse conceito em sua versão tradicional.
Mas a pós-verdade é sempre uma posição relativista, que ironiza toda e qualquer verdade? Levando em conta a influência de Trump e da ultradireita estadunidense na ultradireita brasileira, não surpreende que esta opere dentro de uma lógica da pós-verdade (Finguerut \& Souza, 2018). Mas talvez a ironia em relação a toda e qualquer verdade não seja o que realmente predomina, tanto na ultradireita do Brasil quanto na dos Estados Unidos. Talvez seja mais exato falar de ceticismo seletivo: tudo o que é dito pelo meu inimigo é falso e tudo o que é dito pelos nossos é verdadeiro. O termo ceticismo seletivo descreve de maneira mais precisa o posicionamento assumido por José, Ademir e outros participantes desta pesquisa em relação aos discursos da esquerda e da direita.

O próprio Silveirinha (2018, p. 41), falando sobre as direitas estadunidense e européia, parece admitir que não se trata simplesmente de ceticismo em relação a toda e qualquer verdade, quando afirma que "as pessoas crescentemente vivem na sua própria bolha de conteúdo criada pela personalização dos algoritmos dos mídias sociais, que nos alimentam com o conteúdo com que estamos em sintonia, e filtramos conteúdo com que podemos não concordar".

Eurico menciona em sua fala uma formulação central do discurso conservador, aquela segundo a qual a humanidade deve "conservar aquilo que vem sendo experimentado". Descrevendo os conservadores estadunidenses, McLeod (2005) afirma que, para eles, as coisas são do jeito que são por um bom motivo e que os seres humanos devem ser prudentes com as mudanças e abordá-las de forma cautelosa e com zelo. Essa desconfiança em relação à mudança também está presente na fala de Paula quando ela afirma que entre os conservadores" sempre tem aquela preocupação de qualquer mudança a gente analisar".

Esses conservadores, os estadunidenses e os participantes desta pesquisa, nada mais fazem do que atualizar, quando demonstram preocupação com as consequências da mudança social, as ideias de Edmund Burke, grande expoente da literatura conservadora, expostas em Reflexões sobre a Revolução em França (Burke, 1790/1997).

Burke alertava contra os perigos da "democracia em abstrato", além de questionar o caráter racionalista e idealista da revolução francesa, salientando não se tratar simplesmente da queda da 
velha ordem provocada pela revolução, mas da deslegitimação dos valores tradicionais, da transformação abrupta da sociedade que destruía tudo o que se herdou do passado (Kinzo, 2001).

Não se deve esquecer o caráter contextual dos discursos aqui produzidos. Em outros contextos, militantes conservadores bolsonaristas defendem a ruptura institucional e uma mudança radical na ordem social brasileira, aproximando-se, assim, de uma posição revolucionária (Lessa, 2020). Mas até mesmo no contexto das entrevistas deste estudo, os conservadores produziram, algumas vezes, discursos que pareciam debochar dos valores compartilhados por uma parte significativa da sociedade. Assim, em alguns momentos, essa mesma direita é construída como um movimento de combate à ordem existente, transgressivo e contestador. O conservadorismo de direita seria, nas palavras de Eurico, o "novo sexy", uma alternativa ao progressismo da esquerda e aos movimentos mais liberais da direta, "a nova contracultura".

Toda construção identitária é performativa e constitutiva, procura viabilizar um determinado modo de compreender o mundo. Construções identitárias são projetos para o futuro (Reicher \& Hopkins, 2001). Nesse sentido, a descrição da direita conservadora como um "novo sexy", que atrai novos adeptos em razão de seu caráter supostamente transgressivo em relação à ordem dominante, poderia ser entendida como um projeto para o futuro; futuro que Eurico busca constituir quando descreve assim a direita.

Mas é possível que descrições desse tipo já estejam atuando para manter e ampliar o que talvez já não seja um mero projeto. É possível que a fala de Eurico esteja reproduzindo um modo de compreender e sentir o mundo já estabelecido para amplos setores da sociedade brasileira, principalmente para os jovens. Os palavrões de Olavo de Carvalho, guru da direita conservadora brasileira, contra os inimigos do conservadorismo e a retórica agressiva de Jair Bolsonaro contra os grupos minoritários de esquerda podem estar exercendo uma atração poderosa numa geração de jovens que foi socializada num mundo marcado pelo combate incessante das minorias às formas de desqualificação das sociedades tradicionais contra negros, mulheres, gays etc. Esse discurso conservador talvez esteja sendo bem sucedido no processo de construir essas minorias (e a esquerda em geral) como opressivas, limitadoras e puritanas; ao mesmo tempo em que constrói o conservadorismo como um movimento que libera um discurso pleno, livre de impedimentos, de proibições, que pode xingar, ridicularizar, debochar.

As falas acima mostram a relação tensa dos conservadores com o Estado. Seguindo o conservadorismo estadunidense presente no Tea Party, movimento ultraconservador que inspira o conservadorismo brasileiro atual (Delcourt, 2016), esses militantes advogam o livre mercado e tendem a combater intervenções estatais na economia. Por outro lado, defendem a necessidade de intervenção estatal para conservar práticas tradicionais, como afirma Carlos Eduardo, para conservar "coisas que o Estado já vem protegendo até hoje".

Essa relação dos conservadores com o Estado se manifesta claramente nas críticas que tecem aos libertários de direita. A desconfiança conservadora, inspirada em Burke, em relação às mudanças abruptas e o elogio da manutenção daquilo que vem sendo tradicionalmente experimentado na sociedade não são mobilizados somente para rechaçar o pensamento de esquerda.São mobilizados também para combater propostas da direita política que advoguem uma mudança radical na ordem do mundo. Paula, por exemplo, critica implicitamente os liberais ao afirmar que também defende o Estado mínimo, mas que se deve ter cuidado com as consequências da mudança. José, por sua vez, critica os libertários, em sua versão anarcocapitalista, categorizando-os como "marxistas com sinal inverso" que propõem uma ordem social utópica, uma sociedade sem Estado e totalmente regulada pelo mercado.

Como já foi dito, dois militantes de direita se categorizaram como libertários. Em suas falas, eles tornaram seus os discursos de "ícones" do pensamento libertário como Murray Rothbard (Rothbard, 2010) e Hans-Hermann Hoppe (Hoppe, 2014).

Um dos grandes ícones e nomes do libertarianismo é o Hans-Hermann Hoppe e ele é um conservador, então ele não é um conservador no sentido político de instituições conservadores e tal, ele vai concordar na redução extrema do Estado até mesmo a um certo tipo de anarquia, porém ele também tem o seu pensamento mais refinado no sentido de que não se deixa levar por esse tipo de ideologia que deriva de uma mentalidade marxista, então eu acho que os libertários se eles se colocarem sempre em posições, em locais, em âmbitos de cultura derivado do marxismo, eles vão acabar também como os liberais supervalorizando essas questões de minoria, porém eu não vejo assim, dentro dos 
ícones grandes do libertarianismo, um apoio a essa questão (Emerson).

Na minha concepção da palavra liberal, liberal é quem defende liberdade, só que comumente é usado no Brasil, o liberal é usado para defender o liberal clássico que defende que o Estado deve ter três funções básicas, saúde, educação e segurança. Existem dois tipos de libertários: o Anarquista e o Minarquista. O Minarquista é o que defende que o Estado deve prover só justiça e segurança e eu acredito que o Estado não devia existir (César).

Os libertários, eles vão divergir muito, porque existem libertários em certos graus. Então o grau máximo do libertarianismo é o anarcocapitalismo o qual é entendido o Estado como um ente que deveria desaparecer. E aí se você for regredir nesses graus, você vai ter libertários que defendem uma certa estrutura estatal apenas para defesa externa do país, então, um exército, uma marinha, uma aeronáutica, vai ter libertários que defendem a questão de uma segurança também interna, o Estado como o organizador da justiça, como organizador da urbanização, ou seja, das vias, do trânsito etc. E nesse englobamento você tem realmente o pensamento libertário, agora você dificilmente vai ver um libertário defendendo Estado em saúde, em educação, em apoio a moradia, alimentação, esse tipo de coisa realmente o libertário ele vai passar longe (Emerson).

O libertário pode defender a secessão que é, por exemplo, você dividir, por exemplo, a gente é o Brasil, divida o Nordeste como se fosse um Estado autônomo e a partir disso dividir a Paraíba, depois Campina Grande, pra maioria dos libertários essa é a melhor forma de se conseguir chegar a uma anarquia (César).

Os liberais de certa forma eles vão estar mais alinhados ao pensamento libertário, porém eles acabam tendo muita influência também do pensamento progressista, portanto você vai ter liberais que são a favor do aborto, você vai ter liberais que vão entender a sociedade como oprimidos e opressores, apesar deles não serem marxistas, mas eles vão entender que "ah eu sou liberal, mas nós temos que defender, por exemplo, questões de minorias", então eles tendem a supervalorizar a opressão feminina, que de fato existe, mas que no meu pensamento, e no pensamento conservador também, não é uma questão de importância nacional. É uma questão simplesmente de é... o ser humano é um ente mal e ele vai ter conflitos, então existem conflitos entre os gêneros masculino e feminino, claro que existe, mas esses conflitos não se dão de forma institucional por um patriarcado e sim de forma pontual, ou seja, vai ter homens que vão sempre estar do lado das mulheres e vai ter homens que vão menosprezar as mulheres. Então eu acho que os liberais, eles, infelizmente, supervalorizam algumas questões culturais que a esquerda tem colocado, como, por exemplo, o racismo que existe assim como o pensamento feminista, também, o racismo existe, porém não acho que seja uma cultura impregnada em todos os brasileiros, eu não acho que o brasileiro em si ele é racista, eu acho que alguns brasileiros são racistas, mas isso aí não vai ser solucionado com movimento social que queira usar da censura ou dessa forma para mudar essa realidade (Emerson).

O anarcocomunismo, que é o anarco de esquerda, ele prega o fim além do Estado de outras instituições sociais como família, como igreja, outras questões sociais e que o indivíduo deve ser totalmente livre dessas coisas. Eu não acredito nisso, eu acredito que o Estado é a única instituição coercitiva que lhe coage com armas, com leis, com violência a fazer certas coisas. Acho que a diferença é essa, e as formas de se chegar também. O anarquismo de esquerda prevê o Estado cada vez maior até chegar o momento que não precise mais do Estado e se chega ao anarquismo. Já o de direita prevê a diminuição, talvez gradativa, até se chegar a um estágio que não tenha (César).

Nas falas supracitadas, pode-se notar várias formulações que constituem o discurso libertário. Destaca-se a expressão reiterada de estadofobia, sentimento que eles compartilham com os anarquismos de esquerda. Nas falas de César, a estadofobia se apresenta em sua forma mais extrema, o anarcocapitalismo: "o Minarquista é o que defende que o Estado deve prover só justiça e segurança e eu acredito que o Estado não devia existir". Para ele, "o Estado é a única instituição coercitiva que lhe coage com armas, com leis, com violência a fazer certas coisas". Ecoa, em formulações como essa, 
o discurso repetido por intelectuais anarcocapitalistas, como Rothbard (2010) e Hoppe (2014), que definem o Estado como uma instituição criminosa.

César diferencia o anarquismo de direita do anarquismo comunista. Ambos pregariam o fim do Estado, mas "o anarcocomunismo", diferentemente do anarcocapitalismo, pregaria também o fim "de outras instituições sociais como família, como igreja...”.

A diferença apontada por César entre um libertarianismo soft (o minarquismo) que aceita um Estado provedor de justiça e segurança (e nada mais) e um libertarianismo radical (o anarcocapitalismo) que prega a eliminação do Estado, diz respeito a uma diferenciação no interior do libertarianismo ao longo do século XX. Como argumenta Passetti (2013), desde o fim da Segunda Guerra Mundial, mais precisamente desde o Colóquio Walter Lippmann, os neoliberais passaram a se chamar libertários. Mas é fato que os neoliberais sempre reconheceram a necessidade do Estado, ainda que um Estado mínimo. A partir dos anos 1960, Rothbard (2010), discípulo de Ludwig von Mises, um dos pais fundadores do neoliberalismo, passou a usar o termo libertarianismo para pregar um capitalismo puro, sem mediação estatal, um anarcocapitalismo.

Asfalas deCésar eEmerson mostrama atração exercida sobre eles pelo libertarianismo de Hans-Hermann Hoppe (Hoppe, 2014), libertarianismo que tem pontos em comum com as vertentes mais radicais do conservadorismo estadunidense. Como relata Emerson, "ele é um conservador", embora deseje "a redução extrema do Estado", "um certo tipo de anarquia”.

Emerson se refere a alguns argumentos polêmicos do pensamento de Hoppe (2014). Esse autor afirma que a monarquia era menos danosa para a liberdade do proprietário individual do que as democracias modernas. Ataca ferozmente as demandas das minorias nas democracias ocidentais e defende que uma comunidade tem o direito de expulsar de dentro de si minorias cujos valores sejam incompatíveis com os seus. A defesa da "secessão" na fala de César é claramente inspirada em Hoppe (2014). Para esse autor, um dos horrores dos Estados nacionais é que ele obriga grupos humanos a conviverem num mesmo espaço físico com outros que lhes são insuportáveis. De acordo com Hoppe (2014), a integração forçada promovida pelo Estado leva ao conflito; então, a melhor forma de preservar a diversidade étnica é permitir que qualquer alteridade seja passível de exclusão.
A aproximação entre o libertarianismo anarcocapitalista e o conservadorismo é reconhecida por Emerson, como se viu, e tanto ele como César afirmam diferenças entre o libertarianismo e o liberalismo. Para César, o Liberal clássico "defende que o Estado deve ter três funções básicas, saúde, educação e segurança" e para ele, como libertário, o Estado "não devia existir". Emerson, por sua vez, fundamenta a diferença na pauta cultural das duas correntes de direita e posiciona explicitamente o liberalismo como muito próximo à esquerda: "eu acho que os liberais, eles, infelizmente, supervalorizam algumas questões culturais que a esquerda tem colocado, como, por exemplo, o racismo...."

Mas as diferenças em relação ao conservadorismo também são ressaltadas. Em outro momento de sua entrevista, Emerson afirma que os conservadores "não têm uma certa preocupação de reduzir ao máximo o poder do Estado, a preocupação é com a saúde cultural do país". Emerson reproduz aqui um argumento presente em Hoppe (2014), segundo o qual o conservadorismo moderno é um defensor do Estado e padece do mesmo mal que o liberalismo, que é justamente não defender o fim do Estado.

$\mathrm{O}$ autor anarcocapitalista que inspira os dois universitários que se definiram como libertários não esconde seu horror em relação às democracias de massa que caracterizam os Estados nacionais do Ocidente no século XX. Esse horror tem uma óbvia relação com o poder relativo das classes populares sobre o poder político, na medida em que este poder deve distribuir uma parte da riqueza produzida por toda a sociedade entre os membros dessas classes - porque depende dos votos deles para continuar no poder. A leitura de Democracia, o Deus que falhou de Hoppe (Hoppe, 2014) não deixa dúvidas: para ele, o Estado democrático é insuportável porque é um gigantesco dispositivo mediador que impede uma dominação sem subterfúgios dos donos do poder.

Por fim, uma terceira corrente de direita mencionada pelos entrevistados é o liberalismo, embora o termo liberal não tenha sido usado por nenhum dos entrevistados como categoria de autoidentificação.

Liberal é aquele que defende atuação mínima do Estado em todas as questões, certo? É aquele cara que "ah sou a favor de liberar aborto, sou a favor de liberar drogas, porque o Estado não tem que decidir isso", certo? (Paula). 
Com relação a certos liberais e libertários eu já tive alguns atritos é... assim, questão de opinião, nada físico, nada, nada desse nivel, mas assim que... com alguns... alguns liberais e com alguns libertários, por quê? Porque, assim, quando você fica muito preso a conceitos, que é uma opinião que eu tenho sobre diversos liberais, não todos, eu conheço alguns que não, mas quando você fica preso a conceitos você esquece da complexidade da realidade, porque a realidade não é simplesmente você pegar o que tem no livro $e$ no livro de Adam Smith, que eu admiro muito, na minha opinião é o melhor liberal clássico que já existiu,é Adam Smith, mas não tem como você pegar qualquer conceito do livro e querer aplicar aquilo na prática, na realidade, de uma forma idêntica, porque não é assim. Então... o que éque acaba gerando como consequência, eles, esses certos liberais, libertários, eles deixam de votar ou então de apoiar o que seria o menos ruim para apenas criticar e acabar fazendo o jogo que a esquerda quer (José).

Então, assim, toda a pauta de conservadores, questão de armamento, questão de conservação de certos costumes da sociedade ocidental, eu acredito que certos liberais não defendem, que eles defendem mais a não participação do Estado em nada e eu não acredito nisso, ou pelo menos eles acreditam na não participação em muita coisa que eu acredito que tem que participar (José).

Enquanto os liberais eles... pelo menos a minha visão que eu tenho dos liberais, é que em muitos assuntos eles acreditam que a simples não presença do Estado já resolveria e tudo se resolveria com o mercado, mas eu acredito que o mercado, ele é uma consequência de ações morais, então, assim, o mercado ele vem depois da moralidade. Então... os liberais, muitos deles acreditam que é o inverso, que... é o mercado que dita tudo e eu acredito que são os costumes que ditam o mercado (José).

Alguns liberais vão se colocar a favor do Bolsonaro [na eleição presidencial de 2018] a partir do momento que o Bolsonaro se colocar a favor de liberdades econômicas, então os liberais vão tá apoiando ele (Emerson).
Como se pode observar, os conservadores Paula e José, cujas falas são reproduzidas acima, têm uma relação tensa com o liberalismo. De acordo com Paula, "liberal é aquele que defende atuação mínima do Estado em todas as questões, é aquele cara que 'ah sou a favor de liberar aborto, sou a favor de liberar drogas, porque o Estado não tem que decidir isso"'. Como conservadora, Paula se afasta dos liberais porque não aceita a ideia de não intervenção do Estado nos costumes. José, outro conservador, quando afirma que os liberais ficam presos a conceitos e esquecem "a complexidade da realidade", posiciona como pragmática a ação política dos conservadores e como pouco realista a ação política dos liberais e libertários, cuja falta de realismo acarreta fazer "o jogo que a esquerda quer".

Ao advogar a intervenção do Estado nos costumes, eles estão negando a crença liberal segundo a qual todas as relações sociais podem ser reguladas pelo mercado. José ressalta isso claramente quando afirma que "os liberais muitos deles acreditam que é o inverso, que é o mercado que dita tudo e eu acredito que são os costumes que ditam o mercado". Esses militantes conservadores exaltam o livre comércio, mas, ao advogar a intervenção do Estado nos costumes, demonstram ansiedade diante das possíveis transformações sociais que poderiam advir da dinâmica do mercado.

As críticas dos militantes conservadores aqui entrevistados em relação ao liberalismo não visam o liberalismo econômico: o que criticam de fato é o apego do liberalismo à liberdade político-social.

De fato, esses militantes conservadores desconfiam profundamente do apego do liberalismo à liberdade político-social. Por outro lado, Emerson, o militante libertário, não parece acreditar nesse apego dos liberais à liberdade político-social. Ele não constrói todos os liberais brasileiros como um grupo político para o qual a liberdade político-social seria um princípio fundamental. Quando ele afirma que "alguns liberais vão se colocar a favor do Bolsonaro [na eleição presidencial de 2018] a partir do momento que o Bolsonaro se colocar a favor de liberdades econômicas", constrói tacitamente esses liberais como pessoas para as quais a liberdade que realmente importa é a liberdade para fazer negócios, levando-se em conta que Bolsonaro não é reconhecido por seu apego às liberdades políticas (Lessa, 2020; Reis, 2020). 
Para Merquior (1991), a corrente liberal que ele denomina de liberista sempre teve muito mais apego ao liberalismo econômico do que ao liberalismo político. O caso de Ludwig von Mises, ídolo de todas as vertentes liberais que defendem o Estado mínimo, ilustra a falta de apego de alguns liberistas à democracia liberal. De acordo com Augusto (2014), Mises tinha simpatia pelo fascismo, apesar de ser de origem judaica. Segundo ele, Mises atribuía ao fascismo o papel de salvador da civilização europeia contra o comunismo, aceitava uma "suspensão temporária" da democracia e compreendia a ditadura emergencial como uma opção necessária para o restabelecimento do capitalismo e a manutenção da ordem e da propriedade privada.

A identidade que essa militância estudantil de direita constrói para si própria e para a direita em geral, identidade marcada por contradições, conflitos, tensões, suscita uma questão. O que daria unidade a esses agrupamentos políticos tão diferentes entre si? Para os conservadores e libertários cujos discursos foram analisados aqui, o direito de propriedade se apresenta como um valor fundamental. Em nenhum momento, em todas as entrevistas, eles relativizaram o direito de propriedade. Como reconhece Merquior (1991), os adeptos do liberalismo social relativizam o direito de propriedade, mas na universidade em que foi realizado este estudo não foram identificados militantes do liberalismo social.

Uma outra maneira de dar unidade a essa militância é olhar para seu exterior antagônico, para a instância que a antagoniza e paradoxalmente a constitui. Para a teoria do discurso de Laclau e Mouffe (2015), o que leva as diferenças a aplicarem uma lógica da equivalência não é o caráter positivo que talvez elas compartilhem, mas sim a instância negativa contra a qual elas lutam simultaneamente, constituindo assim uma cadeia de equivalências. Nos grupos aqui estudados, a instância negativa é a esquerda.

\section{Considerações finais}

Este estudo procurou compreender como a militância estudantil de direita numa universidade pública brasileira define a si mesma e a direita política. Alguns entrevistados se autocategorizaram como adeptos de uma direita pautada e regida por uma ordem moral transcendental; outros, como adeptos de um libertarianismo que prega o fim do Estado, o direito de secessão e o direito de propriedade como o valor central da vida social.

Observou-se que os conservadores e os libertários apresentam contradições próprias do discurso que os constituiu. O primeiro grupo busca conciliar o conservadorismo nos costumes e o liberalismo econômico. Pedem que o Estado regule e controle práticas sexuais e outras práticas que dizem respeito à vida privada, mas querem o Estado distante das relações econômicas. O segundo prega o fim do Estado e uma sociedade de capitalismo puro, sociedade de livre comércio e trocas voluntárias, mas apresenta em seu discurso um elemento próprio de sociedades tradicionais (e contrário ao internacionalismo capitalista), que é a defesa do direito de um grupo de expulsar de dentro de si aqueles grupos que ele não suporta, a secessão no discurso libertário.

A militância desses novos atores na cena universitária e na cena brasileira de uma forma geral é uma das consequências mais importantes dos acontecimentos que tiveram início em junho de 2013. Vieram para ficar e possivelmente contribuirão para a manutenção da polarização que caracteriza a política brasileira dos últimos anos.

Durante as entrevistas, os estudantes se mostraram muito interessados em falar sobre si próprios enquanto membros da direita. Embora desconfiados em relação ao modo como os pesquisadores relatariam aquilo que formulavam, pareciam interpretar as entrevistas como uma oportunidade de dar visibilidade às suas definições de si próprios e de seus adversários/inimigos.

Conscientes como são acerca dos efeitos do contexto na produção de discursos, os pesquisadores não ignoravam que eram representados por esses militantes como pessoas que pertenciam ao campo da esquerda política e que essa representação condicionava o conteúdo e a forma das produções discursivas desses militantes. Os pesquisadores, simpatizantes de diferentes vertentes de esquerda, também estavam conscientes, em todas as fases da pesquisa, de que a identificação com um campo político pode produzir interpretações estereotipadas e simplistas de falas e ações de grupos que se situam em um campo político adversário. Por isso, fizeram um esforço sincero para contar uma história que fizesse justiça ao caráter multifacetado dos relatos dos militantes de direita aqui investigados. 


\section{Referências}

Abreu, J. M., \& Allegretti, G. (2016). Comportamento político violento e avanço global da direita: uma análise do caso brasileiro. Crítica e Sociedade: revista de cultura política, 6(2), 88- 121. http://www.seer.ufu.br/index.php/ criticasociedade/article/view/36545

Anderson, P. (1995). Balanço do neoliberalismo. In E. Sader \& P. Gentili (Orgs.), Pós-neoliberalismo: as políticas sociais e o Estado democrático (pp. 9-23). Paz e Terra.

Antaki, C., \& Widdicombe, S. (2008). Identity as an achievement and as a tool. In C. Antaki \& S. Widdicombe (Eds.), Identities in talk (pp. 1-14). Sage.

Augusto, A. G. (2014). O que está em jogo no “mais Mises, menos Marx". Marx e o Marxismo, 2(3), 417-425.

Benwell, B., \& Stokoe, E. (2006). Discourse and identity. Edinburgh University Press.

Billig, M. (1987). Arguing and Thinking: A rhetorical approach to social psychology. Cambridge University Press.

Brenner, A. K. (2011). Militância de jovens em partidos políticos: um estudo de caso com universitários [Tese de Doutorado, Universidade de São Paulo]. Biblioteca Digital de Teses e Dissertações da USP.

Brugnago, F., \& Chaia, V. (2015). A nova polarização política nas eleições de 2014: radicalização ideológica da direita no mundo contemporâneo do Facebook. Aurora: revista de arte, mídia e política, 7(21), 99-129.

Burke, E. (1997). Reflexões sobre a revolução em França. Universidade de Brasília. (Original publicado em 1790).

Condor, S., Tileaga, C., \& Billig, M. (2013). Political rhetoric. In L. Huddy, D. O. Sears \& J. S. Levy (Eds.), The Oxford Handbook of Political Psychology (pp. 262-300). Oxford University Press.

Delcourt, L. (2016). Um TeaParty tropical: a ascensão de uma "nova direita" no Brasil. Lutas Sociais, 20(36), 126-139.

Edwards, D. (2008). The relevant thing about her: social identity categories in use. In C. Antaki \& S. Widdicombe (Eds.), Identities in talk (pp. 15-33). Sage.

Finguerut, A., \& Souza, M. A. D. de. (2018). Que direita é esta? As referências a Trump na nova direita brasileira PósMichel Temer. Revista Tomo, (33), 229-270. https://seer.ufs.br/index.php/tomo/article/view/9357

Gill, R. (2002). Análise de discurso. In M. W. Bauer \& G. Gaskell (Orgs.), Pesquisa qualitativa com texto, imagem e som (pp. 244-269). Vozes.

Hoppe, H.-H. (2014). Democracia, o Deus que falhou: A economia e a política da monarquia, da democracia e da ordem natural. Instituto Ludwig von Mises Brasil.

Jenkins, R. (2004). Social Identity. Routledge.

Kinzo, M. D. G. (2001). Burke: a continuidade contra a ruptura. In F. C. Weffort (Org.), Os Clássicos da Política: Burke, Kant, Hegel, Tocqueville, Stuart Mill, Marx (pp. 13-45). Ática.

Laclau, E., \& Mouffe, C. (2015). Hegemonia e Estratégia Socialista: Por uma política democrática radical. Intermeios.

Latour, B., \& Woolgar, S. (1997). A vida de laboratório: A produção dos fatos científicos. Relume Dumará.

Lessa, R. (2020). Homo bolsonarus: de como nasceu e se criou o confuso e perigoso animal artificial que encarna momentos arcaicos da sociabilidade brasileira. Serrote, n. esp., 46-67.

Madeira, R. M., \& Tarouco, G. da S. (2011). Esquerda e direita no Brasil: uma análise conceitual. Revista Pós Ciências Sociais, 8(15), 171-185.

Martins, L. (13 nov. 2016). À direita, MBL disputa espaço entre estudantes. Estadão. https://politica.estadao.com.br/ noticias/geral,a-direita-mbl-disputa-espaco-entre-estudantes,10000088058

Marx, K., \& Engels, F. (1998). A ideologia alemã. Martins Fontes.

McLeod, A. (2005). Great conservative minds: A condensation of Russell Kirk's "The Conservative Mind". Alabama Policy Institute.

Merquior, J. G. (1991). O Liberalismo: antigo e moderno. Nova Fronteira. 
Passetti, E. (2013). Natureza, pensamento e política. Ecopolítica, (7), 33-59.

Pinto, L. C. (2019). Bolsonaro e os Quartéis: A loucura com método [Texto para Discussão n. 006]. Instituto de Economia da UFRJ. https://www.ie.ufrj.br/images/IE/TDS/2019/TD_IE_006_2019_PINTO.pdf

Pomerantz, A. (1986). Extreme Case formulations: A way of legitimizing claims. Human Studies, 9, 219-229

Potter, J. (1998). La representación de la realidad: Discurso, retórica y construcción social. Paidós.

Potter, J., \&Wetherell, M. (1987). Discourse and Social Psychology: Beyond Attitudes and Behaviour. Sage.

Reicher, S., \& Hopkins, N. (2001). Self and Nation. Sage.

Reis, D. A. (2020). Notas para a compreensão do bolsonarismo. Estudos Ibero-Americanos, 46(1), 1-11. https://doi.org/10.15448/1980-864X.2020.1.36709

Rocha, C. (2019). "Imposto é roubo!" A formação de um contrapúblico ultraliberal e os protestos pró-impeachement de Dilma Rousseff. Dados, 62(3), 1-42. https://doi.org/10.1590/001152582019189

Rorty, R. (1994). A filosofia e o espelho da natureza. Relume-Dumará.

Rothbard, M. N. (2010). A Ética da Liberdade. Instituto Ludwig von Mises Brasil.

Safatle, V. (2017). Só mais um esforço. Três Estrelas.

Sales, A. L. L. de F., Fontes, F. F., \& Yasui, S. (2018). Para (re)colocar um problema: A militância em questão. Trends in Psychology, 26(2), 565-592. https://doi.org/10.9788/tp2018.2-02pt

Santos, F. L. B. dos. (2018). Do lulismo a Bolsonaro: a agonia da nova república no Brasil. Boletín Onteaiken, 26, 1-16. http://onteaiken.com.ar/ver/boletin26/onteaiken26-01.pdf

Silveirinha, M. J. (2018). Bolhas de verdade: cinco alfinetes para (re)construir a democracia. Estudos em Comunicação, 2(26), 35-45. https://doi.org/10.20287/ec.n26.v2.a03

Van Dijk, T. A. (1987). Communicating racism: ethnic prejudice in thought and talk. Sage.

Vinuto, J. (2014). A amostragem em bola de neve na pesquisa qualitativa: um debate em aberto. Temáticas, 22(44), 203-220. https://doi.org/10.20396/tematicas.v22i44.10977

Wetherell, M. (2008). Subjectivity or psycho-discursive practices? Investigating complex Intersectional Identities. Subjectivity, 22, 73-81.

Wetherell, M., \& Potter, J. (1992). Mapping the language of racism: discourse and the legitimation of exploitation. Harvester/Wheatsheaf; Columbia University Press.

\section{Renan Silva de Sousa}

Doutorando em Psicologia Social pela Universidade Federal da Paraíba (UFPB), João Pessoa - PB. Brasil.

E-mail: tfcrenansilva@gmail.com

(1) https://orcid.org/0000-0002-7439-4394

Pedro de Oliveira Filho

Doutor em Psicologia Social e Professor Associado da Unidade Acadêmica de Psicologia da Universidade Federal de Campina Grande (UFCG), Campina Grande - PB. Brasil.

E-mail: deoliveirafilhopedro@gmail.com

(1) https://orcid.org/0000-0003-2401-8953

\section{Jônatas Barros Araújo}

Graduado em Psicologia pela Universidade Federal de Campina Grande (UFCG), Campina Grande - PB. Brasil.

E-mail: jonatas.barros.araujo@gmail.com

(1) https://orcid.org/0000-0002-3284-6006 


\section{Dandara Virgínia Machado Vieira}

Graduada em Psicologia pela Universidade Federal de Campina Grande (UFCG), Campina Grande - PB. Brasil.

E-mail: dandaravmachado@gmail.com

(i) https:// orcid.org/0000-0003-4458-0302

Endereço para envio de correspondência:

Universidade Federal de Campina Grande. Av. Juvêncio Arruda, 795, Bairro Bodocongó. CEP: 58429-600. Campina Grande-PB. Brasil.

Recebido 26/10/2019

Aceito 06/01/2021

Received 10/26/2019

Approved 01/06/2021

Recibido 26/10/2019

Aceptado 06/01/2021

Como citar: Sousa, R. S. de, Oliveira Filho, P. de, Araújo, J. B., \& Vieira, D. V. M. (2022). A identidade da direita em narrativas de seus militantes numa universidade brasileira. Psicologia: Ciência e Profissão, 42, 1-16.

https://doi.org/10.1590/1982-3703003230399

How to cite: Sousa, R. S. de, Oliveira Filho, P. de, Araújo, J. B., \& Vieira, D. V. M. (2022). The identity of the right-wing in narratives of its militants in a Brazilian university. Psicologia: Ciência e Profissão, 42, 1-16.

https://doi.org/10.1590/1982-3703003230399

Cómo citar: Sousa, R. S. de, Oliveira Filho, P. de, Araújo, J. B., \& Vieira, D. V. M. (2022). La identidad de la derecha en las narrativas de sus militantes en una universidad brasileña. Psicologia: Ciência e Profissão, 42, 1-16.

https://doi.org/10.1590/1982-3703003230399 